\title{
Reluctance to Use Technology- Related Products: Development of a Technophobia Scale
}

\author{
Rudolf R. Sinkovics - Barbara Stöttinger - Bodo B. Schlegelmilch • \\ Sundaresan Ram
}

\begin{abstract}
Executive Summary
Many consumers feel overloaded by the complexity of technology-related products. This renders consumers less open to them and may even lead to an aversion or anxiety toward these kind of products: in other words, so-called technophobia.

This article aims to establish an instrument that measures technophobia. Following a literature review and in-depth interviews with experts, a scale is developed and tested in seven different countries (United States, United Kingdom, France, Spain, India, Mexico, and Austria; total sample size = 1,503 respondents). The three underlying dimensions of the scale - "Personal Failure," "Human vs. Machine Ambignity," and "Convenience"-are discussed, and future research avenues to strengthen the cross-national usability of the scale are identified. (C) 2002 Wiley Periodicals, Inc.
\end{abstract}

\section{INTRODUCTION}

any consumers feel overwhelmed by the technological complexity of new products. This renders consumers less open to innovative technology-related products and may even lead to a negative attitude toward these products. Indeed, most consumers are unaware of all features and applications that a given technology-related product offers (Higgins \& Shanklin, 1992).

Studies show, for example, that one third of Americans owning a VCR never take advantage of one of its main features: recording films while the consumer is not at home. As for other products, about one fourth of Americans feel "very

Rudolf R. Sinkovics [Rudolf.Sinkovics@umist.ac.uk] is Lecturer of International Business at UMIST-Manchester School of Management, United Kingdom. Barbara Stöttinger is Assistant Professor of International Marketing and Management, Wirtschaftsuniversität Wien, Austria. Bodo B. Schlegelmilch is Chair of International Marketing and Management, Wirtschaftsuniversität Wien, Austria. Sundaresan Ram is Associate Professor at Thunderbird, the American Graduate School of International Management, Glendale, Arizona.

Thunderbird International Business Review, Vol. 44(4) 477-494• July-August 2002

(c) 2002 Wiley Periodicals, Inc. • Published online in Wiley InterScience (www.interscience.wiley.com).

DOI: $10.1002 /$ tie. 10033 
In extremes, the aversion may reach a point where people refuse to touch certain products even if offered money. insecure" when setting their digital alarm clock or have never used a personal computer (Rosen \& Weil, 1995). Contrary to frequently expressed opinions, the occurrence of technophobia is not related to age: A survey conducted in the United Kingdom, Japan, and Hong Kong revealed that about half the children queried show considerable signs of fear and aversion when using computers at the age of $\mathbf{5}$. Although the use of computers is strongly enforced in schools, the aversion rates remain the same at age 18 (Brosnan, 1998).

Needless to say, this insecurity renders consumers less open to innovative technology-based products. For some consumers, resistance goes even further: they develop an aversion or anxiety toward technologies and technology-related products. This behavior can be described as technophobia. ${ }^{1}$ In extremes, the aversion may reach a point where people refuse to touch certain products even if offered money (Mitchell 1994).

Marketing technology-related products leads to success only if consumers do not meet the products with resistance (Deschamps and Nayak 1995; Sheth and Ram 1987). Considering the importance of a new product's economic success-and, conversely, the number of unsuccessful launches of technology-related products-it appears crucial to identify factors fostering and inhibiting consumer adoption of such products (Booz Allen Hamilton, 1982; Urban \& Hauser, 1980).

Considerable research has been already devoted to identifying factors that determine the market-introduction success of technology-related products. In this respect, demographic variables such as income, education, and standard of living turned out to be particularly important (Fantapié-Altobelli 1991). However, the role of technophobia in the adoption of technology-related products remains relatively unexplored. This is unfortunate, as those few studies conducted in this area, such as Rosen and Weil (1995), lead to the conclusion that technophobia is a main factor that clearly distinguishes adopters from non-adopters.

Thus, from a managerial perspective: Technophobia is likely to influence product development, lends itself as market-segmentation variable, and offers a basis for developing tailored communication strategies in domestic and international contexts. Thus, the development of an instrument able to measure technophobia independent of specific product categories or national contexts is called for.

${ }^{1}$ In a strict medical sense, "phobia" is a result of the exposure to a feared situation. Usually it is related to an intense anxiety or distress, the symptoms of which commonly include sweating, tremors, flushing, palpitations, and sometimes abdominal discomfort. In this context, we use phobia in a more colloquial context, as an "exaggerated, usually inexplicable, and illogical fear of a particular object, class of objects, or situation." 
Consequently, this article aims to establish an instrument that measures technophobia across boundaries. Based on the analysis of the existing body of literature, a scale is developed and tested in seven different countries. To assess its universality, samples from the United States, the United Kingdom, France, Spain, India, Mexico, and Austria (comprising a total of 1,503 respondents) are analyzed to provide insights into what factors influence technophobia. Following the discussion of the results, the paper concludes with some recommendations on future research avenues.

\section{LITERATURE REVIEW}

Following the scale development process suggested by Churchill (1979), we started specifying the research domain by screening the relevant literature. The Anglo-American literature offers a starting point for the development of a technophobia scale (e.g., Frideres et al., 1983; Heinssen, Glass, \& Knight, 1987; Meier, 1988b; Rosen, Sears, \& Weil, 1987). To a large extent, these contributions took an empirical approach toward technophobia. But despite the use of different synonyms such as techno stress (Brod, 1984), cyberphobia (Rice, 1983), computer aversion (Meier, 1988a), or computer anxiety (Raub, 1982), the findings are largely restricted to "computer" phobia, as computers were used as an anchoring product. Most researchers argued that this approach is justifiable, since computer phobia and technophobia were assumed to relate to the same latent variable (Rosen \& Weil 1990a, 1990b). However, this generalization appears problematic, particularly in an international context. In many countries, the use of computers is largely restricted to a business environment while other technology-related products might be well-disseminated in the general public. Using computers as an anchor product in such countries might produce biased results that may not be attributed to phobic attitudes itself but more to the complete lack of experience with these products. Therefore, the explanatory power of such a scale appears limited.

Notwithstanding this constraint, past research in this field provides a useful starting point. Out of these research efforts, a first definition of computer phobia was developed by Jay (1981, p. 47). He described computer phobia as "the resistance to talking about computers or even thinking about computers, the fear or anxiety toward computers and hostile or aggressive thoughts about computers." Rosen and Weil (1990a) and Rosen, Sears, and Weil (1993) extended this notion and defined computer phobia as a three-dimensional construct. If
Using computers as an anchor product in such countries might produce biased results... 
... technophobia represents a negative psychological reaction toward technology, which can arise in varying forms and intensity. one or more of the following aspects apply, a person would be judged as computer phobic: (a) anxiety about present or future interactions with computers or computer-related technology, (b) negative global attitudes about computers, their operation, or their societal impact, and (c) specific negative sentiments or self-critical dialogues during actual computer interaction or when contemplating future computer interaction. In extensive empirical studies, Rosen and Weil underpinned this three-dimensional definition of the construct. Despite the limitations mentioned above, this definition was often taken synonymously for the construct technophobia and was subsequently used by many authors.

Generally speaking, technophobia represents a negative psychological reaction toward technology, which can arise in varying forms and intensity. However, technophobia does not apply to people who feel uncomfortable or stressed by computers due to a lack of information or experience. These deficiencies can be corrected through additional training and, consequently, do not constitute a psychological problem (Rosen, Sears, \& Weil, 1993).

Research on technophobia was also identified in the German-language literature. However, most contributions are either in the context of general research on phobia or, in a broader context, on society's acceptance or aversion toward new technologies. (The latter studies look into attitudes toward genetic or nuclear engineering.) However, while the notion of phobia implies an irrational aspect to the anxiety, concerns related to genetic or nuclear engineering may not be considered as irrational but as rational judgement of chances and opportunities (Röglin, 1994). Technophobia as an irrational anxiety toward technologies, in contrast, has largely been ignored in the Germanic scientific community (Jaufmann, 1991).

Overall, the most useful contributions to the research objective of this paper have been those of Rosen et al. (1987, 1995). Despite the limitations discussed above (the use of computers as anchor variable), the three subscales developed by Rosen, Sears, and Weil (1987) provide a suitable base for the development of a broader, more general technophobia scale. Along with their definition of technophobia, their ATCS scale encompasses negative global attitudes toward computers; the CARS scale measures anxiety about present or future interactions with computers or computer-related technology; and the CTS scale focuses on specific negative cognitions during computer interaction or when contemplating future computer interaction (Rosen, Sears, \& Weil, 1987). While the CARS and the CTS scale 
were shown to be reliable across multiple countries, the ATCS scale had to be adapted to different cultural contexts. Notwithstanding these adaptations, the ATCS scale produced acceptable reliability measures in the United States only.

As outlined, empirical findings on whether technophobia is a two- or three-dimensional construct are still mixed to date. In particular, one of the most widely used and tested measurement instrument by Rosen, Sears, and Weil (1987) produced inconclusive findings. However, as a starting point for this article, we assume that two fundamental facets depict the construct to be determined: (1) feelings of fear, anxiety, or hostility against certain products, subsumed under the notion of aversion, and (2) negative cognitions about the product usage, which we called diffidence. These two broad dimensions appear suitable to capture the substance of technophobia.

\section{RESEARCH DESIGN}

Based on the conceptual definition derived above and in line with the endeavor to develop a generally applicable scale for measuring attitudes of "technophobic" people, an item-pool was generated. This pool was designed to capture the theoretical dimensions aversion against products and diffidence regarding the usage of certain products. In order to establish initial content validity (Carmines \& Zeller, 1980), the itemgeneration process was facilitated by in-depth expert interviews with fellow researchers. In addition, earlier research on computer usage and computer anxiety (Frideres et al., 1983; Heinssen, Glass, \& Knight, 1987; Meier, 1988a; Röglin, 1994; Rosen, Sears, \& Weil, 1987) was

... findings on whether technophobia is a two- or threedimensional construct are still mixed to date. utilized in the item-generation process.

As reported earlier, past research on technophobia was primarily targeted toward computer usage. Although computer usage was considered to be a proxy for investigating anxiety and aversion against new technological products or advancements, this approach appears to have significant limitations. It can be argued from the outset that employing computer use as anchor stimulus discriminates against certain segments of the population. (For instance, in many countries computers are still primarily used in an office environment; this may bias answers in a sample of the general population.) Therefore, it was attempted to find a product category representing a new technology without suffering these restrictions. During in-depth interviews generating the item pool, a set of potential products was identified that was assumed to be more applicable to the research intentions-for 
example, VCRs, telephone answering machines, fax machines, compact disc players, financial calculators, and ATM machines. After careful consideration, ATM machines were selected as the anchoring product category.

ATM machines were considered to best meet the proposed research intentions, since: (a) automated teller machines are widely available in the countries under scrutiny, (b) their use has become more and more accepted in many countries due to restrictive bank hours and increasing costs of personal banking, and (c) they are easily available

ATM machines were considered to best meet the proposed research intentions... to a large number of people regardless of professional or educational background (Leary, 1998; Leauby, 1998; Schifrin, 1997). However, despite high degree of acceptance and widespread use, there are consumers who seem to be reluctant to use ATM machines. Consequently, this user criterion may well serve as discriminator between "technology aficionados" and technology-averse consumers.

Subsequently, a questionnaire was developed that included items delineating the two dimensions of technophobia, which we identified based on previous findings and the relevant literature. In order to test whether our measure of technophobia yields the same results on repeated trials and to make sure that we are actually measuring what we are aiming for, another item pool measuring "use innovativeness" was included (Price \& Ridgeway, 1983). ${ }^{2}$ The "use innovativeness" or "variety seeking in product use" construct involves the use of previously adopted products in novel ways (Price \& Ridgeway, 1983, p. 679). The concept was initially introduced by Hirschman (1980). As conceptualized by Price and Ridgeway (1983), use innovativeness encompasses five factors (44 items): creativity/curiosity, risk preferences, voluntary simplicity, creative reuse, and multiple-use potential. Originally, each item was operationalized using a seven-point, Likerttype format. In the context of this study, a five-point Likert-type format was used instead. As suggested by Price and Ridgeway, item scores were summed within factors for factor indices and, overall, for a comprehensive use-innovativeness measure.

Care was taken to account for the various equivalence issues involved when dealing with multi-country research units (Douglas \& Craig, 1983; Salzberger, Sinkovics, \& Schlegelmilch, 1999). The final (English) questionnaire was translated and back-translated (Brislin, 1970; Hambleton, 1993) into the respective languages (see below). To ensure equivalence of research methods, the translators were

${ }^{2}$ Subsequently, the "use innovativeness" measure was used to perform a series of reliability and validity checks on the technophobia measure. 
instructed to stick as closely to the original meaning of the questions as possible. However, due to functional differences in the use of ATM cards in certain countries, some descriptive questions had to be modified to fit the specific context; these questions were omitted from cross-national analyses. To ensure equivalence in research administration, data collection was scheduled to take place within a tight time frame (one year); this approach helped to limit the hazards of nonequivalent data sets resulting from timing effects. However, under these time constraints, we were challenged with an ambiguous situation-either to extend the data collection process or accept slightly differing sampling procedures. We decided that the time frame in which the study was conducted was the more important aspect and accepted slightly different sampling frames for the seven countries included in the study. In the United States $(n=93)$, a student sample was taken from the adult student population of a graduate school of business. Sampling only such students from the graduate program was an attempt to neutralize well-known biases due to young age, limited financial resources, and overall student lifestyle (Park \& Lessig, 1977; Robinson, Huefner, \& Hunt, 1991). Student samples were also drawn in Spain $(\mathrm{n}=208)$ and Mexico $(\mathrm{n}$ $=200)$. In Great Britain $(n=278)$, France $(n=172)$ and India $(n=$ 103), samples were drawn from four metropolitan areas and spread throughout the respective countries. In Austria $(\mathrm{n}=449)$ a quota sample was drawn that was representative for the adult population of Austria. Age, gender, and occupation were used as quota descriptors.

The final sample was comprised of 1,503 respondents (see Table 1 ). Given the sampling described above, it is not surprising that a significant bias exists toward young respondents $\left(\chi^{2}=266.381, \mathrm{df}=24, \mathrm{p}\right.$ $=0.000)$. Another potential bias was introduced by the fact that data collection was mainly administered in urban regions. However, these

Table 1. Sample Structure

\begin{tabular}{lcr}
\hline Country & Number & Percent \\
\hline l. U.S. & 93 & $6.2 \%$ \\
2. UK & 278 & $18.5 \%$ \\
3. France & 172 & $11.4 \%$ \\
4. Spain & 208 & $13.8 \%$ \\
5. India & 103 & $6.9 \%$ \\
6. Mexico & 200 & $13.3 \%$ \\
7. Austria & 449 & $29.9 \%$ \\
Total & 1503 & $100.0 \%$ \\
\hline
\end{tabular}




\section{Table 2. Age Distribution of the Sample}

\begin{tabular}{|c|c|c|c|c|c|c|c|c|c|c|}
\hline \multirow[b]{2}{*}{ Country } & \multicolumn{2}{|c|}{$15-20$ yrs } & \multicolumn{2}{|c|}{$21-30$ yrs } & \multicolumn{2}{|c|}{$31-40$ yrs } & \multicolumn{2}{|c|}{$41-50$ yrs } & \multicolumn{2}{|c|}{$51-60$ yrs } \\
\hline & tot & $\%$ & tot & $\%$ & tot & $\%$ & tot & $\%$ & tot & $\%$ \\
\hline 1. U.S. & - & - & 82 & $90.1 \%$ & 8 & $8.8 \%$ & 1 & $1.1 \%$ & - & - \\
\hline 2. UK & 18 & $7.3 \%$ & 125 & $50.8 \%$ & 37 & $15.0 \%$ & 46 & $18.7 \%$ & 20 & $8.1 \%$ \\
\hline 3. France & 2 & $1.2 \%$ & 88 & $52.1 \%$ & 51 & $30.2 \%$ & 22 & $13.0 \%$ & 6 & $3.6 \%$ \\
\hline 4. Spain & 27 & $13.6 \%$ & 144 & $72.4 \%$ & 7 & $3.5 \%$ & 17 & $8.5 \%$ & 4 & $2.0 \%$ \\
\hline 5. India & - & - & 49 & $48.5 \%$ & 26 & $25.7 \%$ & 19 & $18.8 \%$ & 7 & $6.9 \%$ \\
\hline 6. Mexico & 17 & $8.8 \%$ & 105 & $54.4 \%$ & 35 & $18.1 \%$ & 27 & $14.0 \%$ & 9 & $4.7 \%$ \\
\hline 7. Austria & 61 & $14.5 \%$ & 122 & $28.9 \%$ & 92 & $21.8 \%$ & 81 & $19.2 \%$ & 66 & $15.6 \%$ \\
\hline Total & 125 & $8.8 \%$ & 715 & $50.3 \%$ & 256 & $18.0 \%$ & 213 & $14.9 \%$ & 112 & $7.9 \%$ \\
\hline
\end{tabular}

effects were not considered to threaten the comparability of the research results, since these structural biases of the samples are consistent across countries.

\section{RESULTS}

\section{Descriptive Information}

The results clearly show that ATM card ownership is widespread in most countries of interest. ATM card ownership is the highest in the U.S. sample ( $98.9 \%$ have ATM cards), followed by the French and UK samples, with $95.3 \%$ and $91.7 \%$, respectively. A relatively low ownership (23.3\%) was only reported in India. ANOVA results confirmed the existence of significant differences with regard to ATM card ownership across countries $(\mathrm{F}=53.739, \mathrm{p}=0.000 \mathrm{~K})$.

With regard to ATM card usage, the data revealed that in the U.S., UK, France, and Austria, cards are most frequently used. In these countries ATM cards are used at least twice, sometimes three times, a week. In contrast, Indian consumers use ATM cards two to three times per month. Significant chi-square results (Pearson $\chi^{2}=$ $292.844, \mathrm{df}=42, \mathrm{p}=0.000 \mathrm{~K}$ ), confirm the differences across countries. The variations in ATM usage might reflect different service development stages. This interpretation is supported by the length of time respondents have been using ATM cards.

In order to test whether aversion or diffidence in the usage of technical equipment might relate to technophobia, additional descriptive information was collected on the use of various technical products (e.g., VCR, business/financial calculator, word proces- 
sor, CD player). Generally speaking, the U.S. respondents were the most frequent users of these product categories, and UK respondents were the second-most frequent users. The differences in the frequency of product usage was later checked in connection with technophobia.

\section{Development of the Technophobia Measure} Exploratory Approach

The first step in developing a cross-national technophobia scale was an exploratory factor analysis. Initial data screening and analysis of correlation patterns (KMO Measure of Sampling Adequacy and Bartlett's Test of Sphericity) for the full sample showed that the data

\section{Table 3. Initial Exploratory Factor Analysis Results for the Full Sample}

\begin{tabular}{|c|c|c|c|}
\hline \multirow[t]{2}{*}{ Rotated Component Matrix } & \multicolumn{3}{|c|}{ Component } \\
\hline & $\begin{array}{l}\text { Personal } \\
\text { failure }\end{array}$ & $\begin{array}{l}\text { Human vs. } \\
\text { machine } \\
\text { ambiguity }\end{array}$ & Convenience \\
\hline I feel inadequate about my ability to use ATMs. & 0.753 & 0.151 & -0.095 \\
\hline Thinking about ATMs makes me nervous. & 0.741 & 0.211 & -0.191 \\
\hline ATMs are intimidating. & 0.741 & 0.209 & -0.222 \\
\hline I wish I were more adept at using ATMs. & 0.684 & -0.097 & 0.111 \\
\hline I worry about making mistakes when using ATMs. & 0.682 & 0.070 & -0.096 \\
\hline I feel frustrated when I use an ATM. & 0.670 & 0.254 & -0.198 \\
\hline I think most people know how to use ATMs better than I. & 0.657 & 0.250 & -0.167 \\
\hline It takes me a long time to complete bank transactions when using an ATM & 0.647 & 0.28 & -0.025 \\
\hline ATMs seem very complicated. & 0.636 & 0.268 & -0.230 \\
\hline I feel some anxiety when I approach an ATM. & 0.620 & 0.146 & -0.184 \\
\hline ATMs agitate me. & 0.609 & 0.309 & -0.196 \\
\hline I find ATMs instructions confusing. & 0.606 & 0.304 & -0.230 \\
\hline ATMs make things too complicated. & 0.556 & 0.473 & -0.278 \\
\hline I want to learn more about using ATMs. & 0.525 & -0.177 & 0.372 \\
\hline I don't trust ATMs with my money. & 0.515 & 0.433 & -0.253 \\
\hline Using ATMs is time-consuming. & 0.481 & 0.374 & -0.070 \\
\hline I feel more confident dealing with a human teller than an ATM. & 0.186 & 0.691 & -0.125 \\
\hline Machines should not handle people's money transactions. & 0.226 & 0.682 & -0.295 \\
\hline I prefer to have people handle my bank activities than to use an ATM. & 0.244 & 0.643 & -0.301 \\
\hline I can conduct my bank transactions without using an ATM. & -0.025 & 0.642 & -0.075 \\
\hline I refuse to use ATMs. & 0.348 & 0.510 & -0.363 \\
\hline I resent that ATMs are becoming so prevalent in our daily lives. & 0.372 & 0.541 & -0.173 \\
\hline I feel comfortable when using ATMs. & 0.024 & -0.359 & 0.686 \\
\hline ATMs are fun to use. & 0.112 & -0.166 & 0.628 \\
\hline I like that ATMs are so convenient. & -0.166 & -0.212 & 0.628 \\
\hline ATMs make bank transactions easier. & -0.155 & -0.231 & 0.598 \\
\hline It is easy to learn how to use ATMs. & -0.324 & -0.029 & 0.558 \\
\hline I feel confident that I could teach someone how to use an ATM. & -0.477 & -0.124 & 0.524 \\
\hline I have no fear of ATMs. & -0.403 & 0.002 & 0.503 \\
\hline
\end{tabular}

Extraction method: Principal Component Analysis. Rotation Method: Varimax with Kaiser Normalization. Rotation converged in 6 iterations. 
set was well-suited for factor-analytic investigations (Churchill, 1991). Principal component analysis and varimax rotation resulted in the extraction of three factors, which extended our initial conceptualization of the construct. Table 3 reports the initial three-factor solution of the exploratory factor analysis on the full sample. The three-factor solution accounts for $50.7 \%$ of the total variance.

Factor I was labeled personal failure because the items (15) loading on this factor predominantly relate to problems, frustrations, and failures when using ATMs. Factor 2 (6 items) represents human vs. machine-ambiguity and fears about machines dominating interactions. Convenience and enjoyment were the main aspects that loaded on factor 3 ( 7 items).

Reliability analysis was performed to check for the internal consistency of the scale (DeVellis, 1991). Seven items were deleted because corrected item-total correlation was below 0.5. Two independent raters were asked to look at the resulting factor structure by assigning the retained items to the three factors personal failure, human vs. machine-ambiguity, and convenience. This procedure was designed to validate the quantitative results in a qualitative way and give a deeper meaning to the factor analysis results. There was a considerable amount of agreement on most items except for four, which were discarded due to semantic similarities to other items. Taken collectively, the described procedure reduced the 3 -factor scale to 18 items. Coefficient alphas are reported in Table 4.

\section{Table 4. Final Technophobia Measure}

Factor: "Personal failure" $(\alpha=0.88)$

I feel some anxiety when I approach an ATM.

ATMs agitate me.

I think most people know how to use ATMs better than I.

I feel frustrated when I use an ATM.

Thinking about ATMs makes me nervous.

ATMs are intimidating.

Factor: "Human vs. machine-ambiguity" $(\alpha=0.80)$

I prefer to have people handle my bank activities than to use an ATM.

I resent that ATMs are becoming so prevalent in our daily lives.

I feel more confident dealing with a human teller than an ATM.

Machines should not handle people's money transactions.

Factor: "Convenience" $(\alpha=0.66)$

I feel comfortable when using ATMs.

ATMs make bank transactions easier.

I like that ATMs are so convenient. 
Measure Purification: Full Sample

To purify the initial three-dimensional factor structure, confirmatory factor analysis was performed on the full sample. ${ }^{3}$ Four additional items were removed from dimension 1 and one item from Dimension 2. These items did not appear to reflect their respective latent factor and had poor loadings. ${ }^{4}$

Content validity (i.e., the adequacy with which the domain of the technophobia characteristic is captured by the measure) was assessed by looking at the standardized solution of the full-model confirmatory factor analysis and could indeed be established. Furthermore, confirmatory factor analysis was used to assess discriminant and convergent validity. ${ }^{5}$

\section{Stability of the Results across Countries}

Multiple-group structural equation modeling was applied in a subsequent step, testing the three-dimensional factor structure across the seven nations. First, no equality constraints were imposed on the groups. Second, the items in the groups were constrained to be equal, in order to test for the metric equivalence of the scale (Mullen, 1995). Metric equivalence is the most stringent form of equivalence and assures that mean scores can be compared across groups. For the unconstrained model, again, the overall fit measures were very good. ${ }^{6}$ Hence, configural invariance of the technophobia measure (Salzberger 1999; Steenkamp and Baumgartner 1998) was established. This shows both that the factor structure is invariant (Buss and Royce 1975; Douglas and Craig 1983) as well as that the measures used were good.?

The application of a constrained CFA model (i.e., a model where seven separate one-group models were calculated with the variables constrained to be equal across all groups) showed again good results, therefore promising metric equivalence. ${ }^{8}$ However, a chi-square dif-

\footnotetext{
${ }^{3}$ We followed standard scale-development procedures, also incorporating recommendations of international researchers.

${ }^{4}$ The proposed model fit the data very well $\left(\chi^{2}=383.075, \mathrm{df}=62, \mathrm{p}=.001\right)$, with a comparative fit index $(\mathrm{CFI}=0.956)$, an incremental fit index $(\mathrm{IFI}=0.957)$, and RMSEA $(0.040)$ well beyond the benchmarks reported in the literature.

${ }^{5}$ All factor loadings were above 0.50 , indicating content validity. A $95 \%$ confidence interval was constructed around the estimates of correlations between the latent constructs to assess discriminant validity. To the extent that the results did not include 1.0, this test provided evidence of discriminant validity, i.e., unique and independent constructs. See appendix for reliability and discriminant validity measurement.

${ }^{\circ} \chi^{2}=1255.600, \mathrm{df}=434, \mathrm{p}=.001 ; \mathrm{CFI}=0.900, \mathrm{IFI}=0.901, \mathrm{RMSEA}=0.037$. Significant chi-squares are related to sample size and pose no problem in the context of this study .

${ }^{7}$ This model served as a baseline model for the subsequent invariance test.

${ }^{8} \chi^{2}=1562.314, \mathrm{df}=512, \mathrm{CFI}=0.872, \mathrm{IFI}=0.873, \mathrm{RMSEA}=0.039$. Although CFI and IFI values of 0.9 to 1 generally are recommended, in sample sizes of less than 200 , these indices are unlikely to achieve the suggested rule-of-thumb benchmarks.
}

The application

of a constrained

CFA model ...

showed again

good results ... 
Table 5. Correlations between Technophobia and Innovativeness

\begin{tabular}{lll}
\hline Pearson Correlations & TP Technophobia & $\begin{array}{l}\text { FI Use } \\
\text { Innovativeness }\end{array}$ \\
\hline TP Technophobia & 1.000 & \\
FI Use Innovativeness & $-0.126^{*}$ & 1.000 \\
\hline
\end{tabular}

${ }^{*}$ Correlation is significant at the 0.01 level (2-tailed).

ference test indicated that the model was significantly different from the baseline model. When releasing some of the constraints for the groups, as suggested by the LM statistic (Bollen 1989), the chisquare difference was still borderline, therefore indicating that only partial invariance of the items was achieved.

The resulting Technophobia measure is shown in Table $4 .{ }^{9}$

\section{Additional Validation Procedures-Use Innovativeness}

Reliability of a measure is a necessary but by no means sufficient condition for the development of a scale (DeVellis, 1991; Lienert, 1989). In order to meet the demands of valid and useful consumer behavior measures (Anderson \& Gerbing, 1988; Churchill, 1979; Jacoby, 1978), the "use innovativeness scale" was included to enable construct validation (Hildebrandt, 1984). The "use innovativeness" measure (Price \& Ridgeway, 1983) was viewed to be a good means of measuring concurrent validity. It was hypothesized that high technophobia scores would go hand-in-hand with low use innovativeness scores. While validity can never be completely proven, any inconsistent results would at least raise doubts about the conceptualization of the technophobia measure developed.

Before using the use innovativeness measure, it was tested for its psychometric properties, in line with the confirmatory procedures outlined above. The factors and the corresponding items used in the confirmatory analysis are reported in Appendix 1 . Innovativeness item scores were summed within factors for factor indices and also summed for an overall use innovativeness measure. The scores were correlated among each other to check for internal consistency. As expected, the innovativeness measure indicated significant correlations between the subscales and between the overall use innovativeness score and the subscales. Therefore, the use

\footnotetext{
${ }^{9}$ Content validity and discriminant validity was checked in line with the procedure outlined above for each of the countries involved. However, due to space limitations, we report the indices for the full data set only.
} 
innovativeness measure showed good psychometric properties and appeared suitable for further validity checks of the technophobia measure.

Hence, correlations were calculated for the use innovativeness measure and the technophobia scale, based on the overall use innovativeness measure score. While we also summed up item scores within factors (Bearden \& Netemeyer, 1999), only the overall correlations are reported for reasons of readability.

As shown in Table 5, the two measures were significantly correlated. The higher a respondent's innovativeness score, the lower the technophobia score, and vice versa. Therefore, this check supported the credibility of the technophobia measure and its cross-national use.

A further indication of the robustness of the technophobia measure was gained from a comparison of different consumer segments in terms of their technophobia scores. As expected of a valid measure, we found that consumers using the technology-based product groups, such as VCRs, calculators, CD players, and word processors, showed lower technophobia scores (see Table 6).

The results indicate consistent behavior of the scale within the different groups of product users and nonusers. This adds to the validity of the previous tests and documents the soundness of the instrument developed.

\begin{tabular}{|c|c|c|c|c|c|}
\hline $\begin{array}{l}\text { Group Statistics } \\
\text { TP Technophobia }\end{array}$ & & $\mathrm{N}$ & Mean & $\begin{array}{l}\text { Std. } \\
\text { Deviation }\end{array}$ & $\begin{array}{l}\text { Std. Error } \\
\text { Mean }\end{array}$ \\
\hline \multicolumn{6}{|c|}{ Frequency of VCR Use* } \\
\hline & $0 \mathrm{NO}$ & 330 & 33.56 & 6.97 & 0.38 \\
\hline & 1 YES & 1031 & 32.53 & 6.45 & 0.20 \\
\hline \multicolumn{6}{|c|}{ Frequency of Business/Financial } \\
\hline \multirow[t]{2}{*}{ Calculator Use* } & $0 \mathrm{NO}$ & 659 & 33.52 & 6.56 & 0.26 \\
\hline & $1 \mathrm{YES}$ & 701 & 32.11 & 6.54 & 0.25 \\
\hline \multicolumn{6}{|c|}{ Frequency of Word Processor Use* } \\
\hline & $0 \mathrm{NO}$ & 621 & 33.17 & 7.03 & 0.28 \\
\hline & $1 \mathrm{YES}$ & 741 & 32.46 & 6.17 & 0.23 \\
\hline \multicolumn{6}{|c|}{ Frequency of CD Player Use* } \\
\hline & $0 \mathrm{NO}$ & 306 & 34.42 & 7.01 & 0.40 \\
\hline & $1 \mathrm{YES}$ & 1054 & 32.31 & 6.39 & 0.20 \\
\hline
\end{tabular}

* Significant technophobia differences between groups at the 0.05 level 


\section{IMPLICATIONS AND FUTURE RESEARCH}

The degree of consumers' technophobia is a major factor influencing the success of technology-related product innovations. Different values of technophobia may serve as an indicator of how inclined consumers are to buy such products. While some previous research efforts were undertaken to capture the complex construct, most studies were confined to single-country settings. Based on seven different country samples, this study attempts to address these limitations by developing a cross-national valid scale for technophobia.

Only in India, the penetration rate of ATM cards has not yet reached the level of other countries.
Moreover, previous research was limited to the investigation of computer use and computer anxiety. In order to extend the scope of research, ATM cards were used as anchor products for technophobia measurement.

The results confirmed the decision to use ATM cards as an empirical setting. Cards have been adopted to an extent that the ownership of a second ATM card is steadily increasing. Only in India, the penetration rate of ATM cards has not yet reached the level of other countries. Looking at the age distribution, ATM users can be found in all age groups, a fact that further confirms the suitability of this product for the development of a technophobia scale.

In developing a cross-nationally valid scale to measure technophobia, attitudes underlying technophobic behavior were investigated. Three dimensions describing technophobia emerged from a factor analysis. The first factor, personal failure, encompasses fears and frustration that arise when getting into contact with technology-related products. The second factor human vs. machine ambiguity, relates to the critical distance of "human" users toward machines. The third factor, convenience, underlines the beneficial effects of ATM card use. Single group and multiple-group-confirmatory factor analysis were applied on the data set and showed a very good fit of the model, which furnishes further evidence in favor of the developed technophobia scale. While only partial metric invariance could be identified, considering the number of samples involved and some sampling differences, the configural and factorial invariance stress the crossnational applicability of the scale. Additional support was provided through validity tests using the well-established use innovativeness scale as well as correlations with several product groups. As expected, consumers who own technology-related products such as a VCR, a $\mathrm{CD}$ player, etc., are less technophobic than nonusers. Correlations between use innovativeness and technophobic attitudes show, in line 
with expectations, that technophobic consumers are also less use innovative and vice versa.

From a managerial perspective, these results offer some promising marketing applications, such as market segmentation and targeting. Based on specific country values on the technophobia scale, country markets may be differentiated as to their openness toward technology-related products. Particularly, when using a stepwise international product rollout, technophobia values may contribute to planning the schedule for introduction. Moreover, as technophobia is an excellent discriminator between adopters and non-adopters, it may well serve as a variable segmenting customer groups. Also, knowledge on consumers' technophobia values may be applied in communication policies. Referring to the three underlying dimensions of the construct, different arguments may be put forward for different consumer groups. Taken collectively, the convenient size of the scale (18 items) renders it highly suitable for a large variety of market research tasks.

Turning to future research, some promising avenues can be identified: First, the scale may be refined further by introducing an extended set of anchor products. These anchor products might be selected in a way so that they represent different stages of technological content. Thus, the scope of applying the scale can be explored in more detail. Also, this would allow a better insight into gradual differences on the technophobia scale. Another promising research avenue would be to consider the time dimension and its effects on an individual's technophobia level. Given the diffusion rates of technologyrelated products, it appears highly interesting to investigate to which extent and in which time frame technophobia levels change over time. For this purpose, a longitudinal research design appears most suitable. From a methodological point of view, the scale's explanatory power may be enhanced by distinguishing between country clusters that show full metric invariance on the scales' items and those exhibiting only partial invariance. This would enable a further finetuning of cross-national comparisons and support the managerial applicability of the measure.

\section{ACKNOWLEDGMENTS}

The authors thank Rosanna Garcia, Thomas Salzberger, and two anonymous reviewers for providing many valuable comments. 
APPENDIX 1. Reliability and Discriminant Validity Measurement

(1)

(1) Personal Failure

(2) Human vs. machine ambiguity

(3) Convenience
0.88

0.677

$(0.020)$

$-0.575$

(0.027)
(2)

0.80

$-0.772$

(0.023)
(3)

\subsection{6}

Inter-factor correlations reported in the lower triangle, Cronbach alphas are reported along the diagonal

Note: The chi-square statistic was significant, but this result was ignored because of the large sample size and well-known chi-square limitations when performed on large sample sizes. Thus, incremental goodness of fit indices were used for interpretation of the model fit. Recommended threshold values of 0.90 were achieved for the Goodness of Fit Index $(\mathrm{GFI}=0.93$ ) and the Adjusted Goodness of Fit Index (AGFI = 0.91). The Normed Fit Index (NFI) was slightly below the threshold value, but overall, the data seemed to fit the model as suggested

\begin{tabular}{|c|c|}
\hline $\begin{array}{l}\text { APPENDIX 2. Innovativeness Measure Tested in the Confirn } \\
\text { Factor Analysis }\end{array}$ & tory \\
\hline item & $+/-$ \\
\hline Factor 1. Creativity/Curiosity & \\
\hline $\begin{array}{l}\text { Knowing how a product works offers almost as much pleasure as knowing that } \\
\text { the product works well. }\end{array}$ & + \\
\hline I am very creative when using products. & + \\
\hline I am less interested in the appearance of an item than in what makes it tick. & + \\
\hline As a child, I really enjoyed taking things apart and putting them back together again. & + \\
\hline Curiosity is one of the permanent and certain characteristics of a vigorous intellect. & + \\
\hline If I can't figure out how something works, I would rather tinker with it than ask for help. & + \\
\hline I like to fix things around the house. & + \\
\hline I have gotten instruction in self-reliance skills (e.g. carpentry, car tune-up, etc.). & + \\
\hline I would rather fix something myself than take it to someone to fix. & + \\
\hline Factor 2. Risk Preferences & \\
\hline $\begin{array}{l}\text { When I try to do projects on my own, I'm afraid I will make a worse mess } \\
\text { of them than if I had just left them alone. }\end{array}$ & + \\
\hline I always follow manufacturer's warnings against removing the back plates on products. & + \\
\hline I find very little instruction is needed to use a product similar to one I'm already familiar with. & - \\
\hline I'm uncomfortable working on projects different from types I'm accustomed to. & + \\
\hline Factor 3. Voluntary Simplicity & \\
\hline I like to make clothing or furniture for myself and my family. & + \\
\hline I often make gifts instead of buying them. & + \\
\hline $\begin{array}{l}\text { When building something, it is better to use things already around the } \\
\text { house than to buy materials. }\end{array}$ & + \\
\hline Factor 4. Creative Reuse & \\
\hline I save broken appliances because I might be able to use the parts from them. & + \\
\hline I enjoy thinking of new ways to use old things around the house. & + \\
\hline When I build something, I can often make do with things I've already got around the house. & + \\
\hline I never throw something away that I might use later. & + \\
\hline $\begin{array}{l}\text { In general, I would rather alter an old product to work in a new situation } \\
\text { than purchase a new product specifically for the purpose. }\end{array}$ & + \\
\hline
\end{tabular}




\section{REFERENCES}

American Psychiatric Association. (1994). Diagnostic and statistical manual of mental disorders (4th ed.). Washington, DC: American Psychiatric Association.

Anderson, J.C., \& Gerbing, D.W. (1988). Structural equation modeling in practice: A review and recommended two-step approach. Psychological Bulletin, 103(3), 411-423.

Baumgartner, H., \& Homburg, C. (1996). Applications of structural equation modeling in marketing and consumer research: A review. International Journal of Research in Marketing, 13(2), 139-161.

Bearden, W.O., \& Netemeyer, R.G. (1999). Handbook of marketing scales- multi-item measures for marketing and consumer behavior research. Newbury Park, CA: Sage Publications.

Bearden, W.O., Sharma, S., \& Teel, J.E. (1982). Sample size effects on chi square and other statistics used in evaluating causal models. Journal of Marketing Research, 19(4), 425-430.

Bollen, K.A. (1989). Structural equations with latent variables. New York: John Wiley \&Sons, Inc.

Booz Allen Hamilton, Inc. (1982). New product management for the 1980's. New York: Booz Allen Hamilton, Inc.

Brislin, R.W. (1970). Back translation for cross-cultural research. Journal of Cross-Cultural Psychology, 1(3), 185-216.

Brod, C. (1984). Technostress: The human cost of the computer revolution. Reading, MA: Addison-Wesley.

Brosnan, M.J. (1998). Technophobia: The psychological impact of information technology. New York: Routledge.

Buss, A.R., \& Royce, J.R. (1975). Detecting cross-cultural commonalities and differences: Intergroup factor analysis. Psychological Bulletin, 82(1), 128-136.

Carmines, E.G., \& Zeller, R.A. (1980). Reliability and validity assessment. Thousand Oaks, CA: Sage Publications.

Churchill, G.A. (1979). A paradigm for developing better measures of marketing constructs. Journal of Marketing Research, 16(1), 64-73.

Churchill, G.A. (1991). Marketing research: Methodological foundations (5th ed.). Chicago: The Dryden Press.

Deschamps, J., \& Nayak, P. (1995). Product juggernauts. Boston: Arthur D. Little.

DeVellis, R.F. (1991). Scale development-theory and applications. Newbury Park, CA: Sage Publications.

Douglas, S.P., \& Craig, S.C. (1983). International marketing research. Englewood Cliffs, NJ: Prentice-Hall.

Fantapié-Altobelli, C. (1991). Die Diffusion neuer Kommunikationstechniken in der Bundesrepublik Deutschland. Erklärung, Prognose und marketingpolitische Implikationen. Heidelberg, Germany: Physica-Verlag.

Frideres, J.S., Goldenberg, S., Disanto, J., \& Fleming, U. (1983). Incidence and potential causal factors. Social Indicators Research, 13(4), 381-393.

Gerbing, D.W., \& Anderson, J.C. (1988). An updated paradigm for scale development incorporating unidimensionality and its assessment. Journal of Marketing Research, 25(2), 186-192.

Hambleton, R.K. (1993). Translating achievement tests for use in cross-national studies. European Journal of Psychological Assessment, 9, 57-68.

Heinssen, R.K., Glass, C.R., \& Knight, L.A. (1987). Assessing computer anxiety: development and validation of the computer anxiety rating scale. Computers in Human Behavior, 3, 49-59.

Higgins, S., \& Shanklin, W.L. (1992). Seeking mass market acceptance for high-technology consumer products. Journal of Consumer Marketing, 9(1), 5-14.

Hildebrandt, L. (1984, February). Kausalanalytische Validierung in der Marketingforschung. Marketing ZFP, 1, 41-51.

Hirschman, E.C. (1980). Innovativeness, novelty seeking, and consumer creativity. Journal of Consumer Research, 7(3), 283-295.

Jacoby, J. (1978). Consumer research: How valid and useful are all our consumer behavior research findings? A state of the art review. Journal of Marketing, 42 (April), 87-96.

Jaufmann, D. (1991). Einstellungen zum technischen Fortschritt: Technikakzeptanz im nationalen und internationalen Vergleich. Frankfurt/Main: Campus Verlag. 
Rudolf R. Sinkovics . Barbara Stöttinger . Bodo B. Schlegelmilch . Sundaresan Ram

Jay, T.B. (1981). Computerphobia: What to do about it? Educational Technology, 21, 47-48.

Leary, C. (1998). Deployment helps CUs compete in ATM market. Credit Union Magazine, 64(7), 19-20.

Leauby, B.A. (1998). Industry. Pennsylvania CPA Journal, 69(1), 5.

Lienert, G.A. (1989). Testaufbau und Testanalyse. München: Psychologie Verlags Union.

Maxwell, R. (1999). Social phobia. [On-line]. Available: http://www.familymedicine.co.uk/ novarticles/socphobia.htm.

Meier, S.T. (1988a). Computer aversion. Computers in Human Behavior, 12, 327-334.

Meier, S.T. (1988b). Predicting individual differences in performance on computer-administered tests and tasks: Development of the computer aversion scale. Computers in Human Behavior, 4, 175-187.

Merriam-Webster Inc. (1999). WWWebster Dictionary. [On-line] Available: http:// www.m-w.com/home.htm.

Mitchell, S. (1994). Technophiles and technophobes. American Demographics, 16(2), 36-41.

Mullen, M.R. (1995). Diagnosing measurement equivalence in cross-national research. Journal of International Business Studies, 26(3), 573-596.

Park, C.W., \& Lessig, V.P. (1977, September). Students and housewives: Differences in susceptibility to reference group influence. Journal of Consumer Research, 4, 102-110.

Price, L.L., \& Ridgeway, N.M. (1983). Development of a scale to measure use innovativeness. In R.P. Bagozzi \& A.M. Tybout (Eds.), Advances in consumer research, (vol. 10, pp. 679-684). Ann Arbor, MI: Association for Consumer Research.

Raub, A. (1982). Correlates of computer anxiety in college students [unpublished doctoral dissertation, University of Pennsylvania].

Rice, B. (1983). Curing cyberphobia. Psychology Today, 17(8), 79.

Robinson, P.B., Huefner, J.C., \& Hunt, K.H. (1991, April). Entrepreneurial research on student subjects does not generalize to real world entrepreneurs. Journal of Small Business Management, 29, 42-50.

Röglin, H.C. (1994). Technikängste und wie man damit umgeht. Düsseldorf: VDI-Verlag.

Rosen, L.D., \& Weil, M.M. (1990a). Computers, classroom instruction, and the computerphobic university student. Collegiate Microcomputer, 8(4), 275-283.

Rosen, L.D., \& Weil, M.M. (1990b). Myths and realities of computerphobia. Anxiety Research, 3, 175-191.

Rosen, L.D., \& Weil, M.M. (1995). Adult and teenage use of consumer, business, and entertainment technology: Potholes on the information superhighway? Journal of Consumer Affairs, 29(1), 55-84.

Rosen, L.D., Sears, D.C., \& Weil, M.M. (1987). Computerphobia. Behavior research methods, instrumentation, \& computers, 19(2), 167-179.

Rosen, L.D., Sears, D.C., \& Weil, M.M. (1993). Treating technophobia: A longitudinal evaluation of the computerphobia reduction program. Computers in Human Behavior, 9, 27-50.

Salzberger, T. (1999). Interkulturelle Marktforschung: Methoden zur Überprüfung der Datenäquivalenz. Vienna: Service Verlag.

Salzberger, T., Sinkovics, R.R., \& Schlegelmilch, B.B. (1999). Data equivalence in cross-cultural research: A comparison of classical test theory and latent trait theory based approaches. Australasian Marketing Journal, 7(2), 23-38.

Schifrin, M. (1997). Who owns the cashless society? Forbes, 159(12), 42-43.

Sheth, J.N., \& Ram, S. (1987). Bringing innovation to market: How to break corporate and customer barriers. New York: John Wiley \& Sons.

Steenkamp, J.-B., \& Baumgartner, H. (1998). Assessing measurement invariance in crossnational consumer research. Journal of Consumer Research, 25(1), 78-90.

Urban, G. \& Hauser, J.R. (1980). Design and marketing of new products. Englewood Cliffs, NJ: Prentice Hall. 